\section{Immundiffusion, doppelte radiale}

R. Westermeier

Freising, Deutschland

Synonym(e) Ouchterlony-Immundiffusion; Immundoppeldiffusion

Englischer Begriff immunodiffusion

Definition Nachweistechnik für Antigene oder Antikörper mittels Immunpräzipitation, bei der beide Reaktionspartner in einem Gel aufeinander zudiffundieren.

Physikalisch-chemisches Prinzip Eine der technisch einfachsten Formen von Immuntests. Eine Glasplatte wird mit einem Gel (Agar-Agar) beschichtet, und in das Gel werden Löcher gestanzt. Antigen- und Antikörperlösung werden in sich gegenüberliegende Löcher getropft, sodass sie gegeneinander diffundieren können. Im Falle einer positiven Reaktion bildet sich ein Präzipitat (Präzipitationslinie).

Einsatzgebiet Die Ouchterlony-Technik wird heute nur noch bei speziellen Fragestellungen eingesetzt. Sie eignet sich besonders zur Reinheitsbestimmung von Antigenen, für das Überwachen der Antikörperantwort bei immunisierten Tieren und für einen Spezifitätsvergleich verschiedener Antikörper. Man kann feststellen, ob zu untersuchende Antigene oder Antikörper mit bekannten Antigenen oder Antikörpern übereinstimmen. Im Falle einer Übereinstimmung gehen die Präzipitationslinien bogenförmig ineinander über, im Falle der Nichtidentität überkreuzen sich die Präzipitationslinien und im Falle der Teilidentität entsteht ein Bogen mit einem Sporn.

Sensitivität Diese Methode kann zwischen 0,1 und $10 \mathrm{~g} / \mathrm{L}$ Antikörper oder Antigen nachweisen. Es ist möglich, durch empfindliche Färbungen und Auswertung mit einem Lupenmikroskop die Nachweisgrenze auf $1 \mathrm{mg} / \mathrm{L}$ zu reduzieren.

Praktikabilität - Automatisierung - Kosten Es ist keine spezielle Apparatur erforderlich und als Reagenzien können gewöhnlich ungereinigte Extrakte eingesetzt werden. Die Durchführung der Methode ist aber mit einem hohen Aufwand verbunden und kaum automatisierbar.

\section{Literatur}

Kemeny DM (1994) ELISA. Gustav Fischer Verlag, Stuttgart, S 7-10 